\title{
Endocrine Disruptors and Breast Cancer
}

\author{
Cathrin Brisken*
}

\begin{abstract}
Breast cancer strikes one out of eight women in Switzerland. The increase in breast cancer incidence over the past 70 years parallels an enormous increase of man-made, persistent chemicals in our environment; some of which have endocrine-disrupting properties in wildlife and/or in animal models. Epidemiological evidence is strong that a woman's risk to get breast cancer is linked to her reproductive history and with that to the changes in her hormonal milieu. Exogenous hormones have also been shown to increase breast cancer risk, however, a causative link between exposure to endocrine disruptors and human disease is difficult establish as many of these compounds are ubiquitous and no unexposed controls exist. The synthetic estrogen, diethylstilbestrol (DES), that was given to pregnant women for three decades, was banned because it was linked to a vaginal carcinoma in their daughters. It has now been shown that not only women who have taken the drug themselves have increased breast cancer risk but also their daughters who were exposed in utero. This indicates that breast cancer risk can be affected by endocrine disruption not only in the adult but already in utero. Evidence from animal models is accumulating that perinatal exposure to environmentally relevant, low doses of a related compound, bisphenol A (BPA), alters breast development and increases breast cancer risk. Given the prevalence of endocrine-disrupting agents they deserve our attention.
\end{abstract}

Keywords: Breast cancer · Breast development · Bisphenol A - Diethylstilbestrol $\cdot$ Estrogen

\section{Breast Cancer: The Facts}

Breast cancer is a complex and multifactorial disease. It comprises 18 distinct histological subtypes $^{[1]}$ and is clinically extremely heterogeneous. As one of the most commonly diagnosed human tumors it strikes one out of eight women in Switzerland, and is a leading cause of cancer death worldwide. ${ }^{[2]}$ Age-adjusted incidence has increased by about $1 \%$ per year from 1940 to 1980 and continues to rise, ${ }^{[3]}$ with a growing number of women below the age of 40 affected by breast cancer in recent years. ${ }^{[4]}$

${ }^{*}$ Correspondence: Prof. Dr. C. Brisken

Ecole polytechnique fédérale de Lausanne (EPFL)

ISREC - Swiss Institute for Experimental Cancer

Research

155, Chemin des Boveresses

$\mathrm{CH}-1066$ Epalinges

Tel.: +41216925851

Fax: +41216526933

E-mail: cathrin.brisken@epfl.ch
Less than $10 \%$ of all breast cancers can be attributed to genetic factors. Some patients are born with a bad version of a gene that predisposes to breast cancer such as BRCA1, BRCA2, p53, or ATM. Such patients typically have a strong family history of breast cancer with various family members affected, with onset of the disease at a young age, and possibly with bilateral disease.

Life-style factors such as alcohol consumption and lack of physical activity have been reported to increase breast cancer risk; ${ }^{[5]}$ obesity is associated with a higher risk in postmenopausal women. ${ }^{[6]}$ The most established risk factors for breast cancer are related to life-time hormone exposure; ${ }^{[7]}$ early menarche, late age at first childbirth and late menopause. ${ }^{[8]}$ All of these are generally associated with only weak or moderate elevations in risk per patient but have largely influenced rates globally. Thus, the particularly large increases in breast cancer incidence observed recently among Hispanic and Hispanic American women are attributed to delayed childbearing.

Not only endogenous hormones may affect breast cancer development but exogenous hormones also bestow an increased risk as studies of women taking the pill and of postmenopausal women on hormone replacement therapy have shown; women currently taking the pill have a 1.24 relative risk ${ }^{[9]}$ and women on hormone replacement therapy have a 1.3 relative risk when taking only estrogens and a 2.0 relative risk when taking estrogens and progesterone. ${ }^{[10]}$

All these factors taken together account only for some of the increase in breast cancer incidence and the question arises whether the growing number of breast cancer cases since the 1940s may also have something to do with the increase in man-made persistent chemicals in our environment that has occurred in parallel. Evidence has accumulated that some of these substances like certain organochlorine compounds, including agricultural pesticides, such as p,p'-dichlorodiphenyltrichloroethane (DDT), chlordane, lindane, dieldrin, and industrial chemicals such as polychlorinated biphenyls ${ }^{[11-13]}$ are biologically active and may disrupt the endocrine system in multiple different ways (see other articles in this issue); they can impair the reproduction of birds, fish and other animals, affect cognitive function, the immune system and many other organs in various animal models. What about their impact on humans, more specifically the breast cancer problem?

\section{Breast Cancer and Endocrine Disruptors}

The correlation between the accumulation of persistent chemicals and an increase in reproductive disorders, such as decreased 
sperm counts (see Germond and coworkers in this issue $\left.{ }^{[14]}\right)$ together with the observations in wild life have raised the concern that there may be a causal link between hormone-dependent cancers and exposure to endocrine disruptors but proofs are difficult to come by. A case has been made for the organochlorine, dieldrin formerly used as an insecticide. A Danish study demonstrated that serum levels of dieldrin were associated with a significantly increased dose-related risk of breast cancer.[15]

Epidemiology identified classical carcinogens and provided the proof that tar, tobacco, and asbestos are causal in the genesis of different malignancies such as testicular, lung and bladder cancers. As persistent chemicals are ubiquitous, epidemiologists are faced with the problem that there are no unexposed 'controls' that would allow them to assess the effects of exposure; even people in remote locations, such as Canada's Baffin Island, harbor traces of PCBs, DDT, and dioxins.

Given the large number of these compounds in our environment - more than 100000 chemicals are registered in the EU - human beings are exposed to a complex mixture of chemicals, that may interact in many different ways. ${ }^{[12,16]}$

Another problem is the long delay between exposure and effect. Cancer is thought to arise from normal cells that evolve into cancer cells passing through different stages, reflected in the multistep/ multigene model of carcinogenesis (Fig. 1). In the case of breast cancer the target cells are the epithelial cells that make up the milk ducts in the breast. The driving forces in tumorigenesis are held to be heritable changes, i.e. mutations, in multiple, independent genes. Mutations may occur spontaneously or as a result of an environmental agent and can take decades to accumulate. Cells may also be altered heritably by epigenetic mechanisms, these confer changes on chromatin and DNA that are stable over rounds of cell division but do not involve changes in the underlying DNA sequence. How epigenetic changes are acquired during tumorigenesis is poorly understood and an area of intense investigation. Of note is that several endocrine disruptors have been shown to elicit epigenetic changes. ${ }^{[17,18]}$

In the case of breast cancer, hormones impinge on this evolution at various stages through as yet poorly understood mechanisms. A subset of the milk duct cells has receptors for estrogens and progesterone and serve as antenna that give out signals to neighboring cells in response to hormonal stimulation. ${ }^{[19]}$ The hormones not only trigger cell proliferation/division but alter the microenvironment, they change intercellular communication, and have systemic effects with secondary consequences for the breast tissue. All these changes are im-

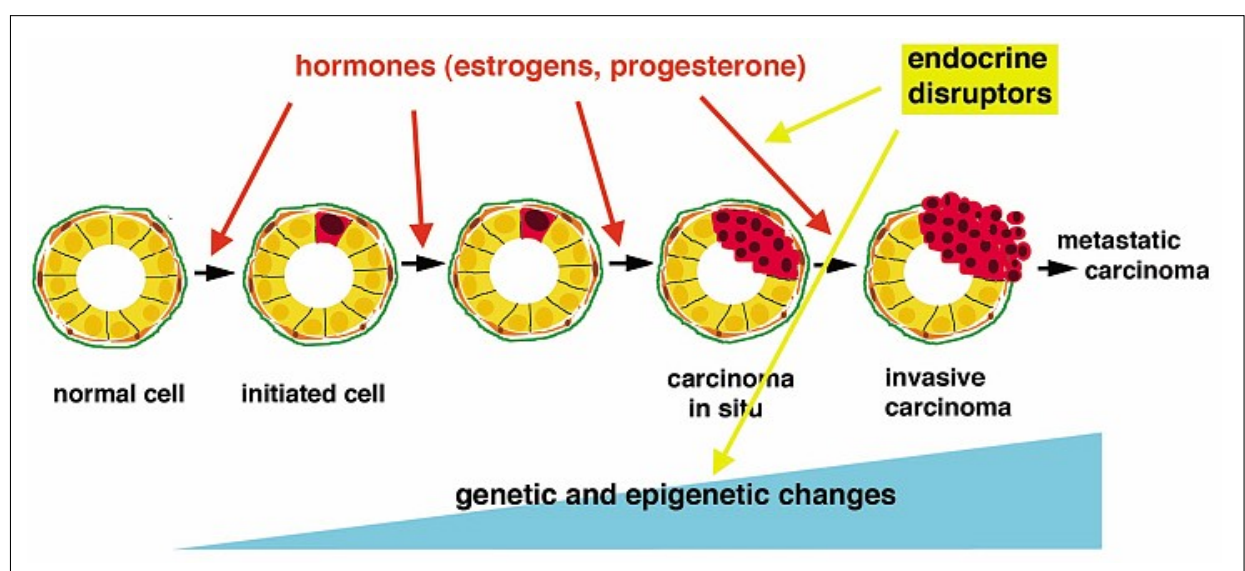

Fig. 1. Schematic representation of multistep carcinogenesis in the breast: Shown are cross sections of a milk duct at different stages of the development of a breast carcinoma. Lumenal epithelial cells (yellow) line the lumen of the milk duct. A layer of elongate myoepithelial cells surrounding the luminal epithelial cells. Both epithelial cell layers are separated from surrounding connective tissue by the basal lamina (green). Genetic and epigenetic changes are acquired as a normal cell turns into a tumor cell. These changes drive alterations in the cell's behaviour. A carcinoma in situ can remain quiescent for many years and eventually break through the basal lamina into the surrounding tissue (invasive carcinoma) and can then seed to distant organ sites (metastasis). Hormones affect the carcinogenic process at all stages (red arrows). Endocrine disruptors interfere with the hormonal regulation at all stages and may more directly affect breast carcinogenesis through epigenetic mechanisms (yellow arrows).

portant for the formation of new milk ducts during normal breast development and may promote progression of breast cancer.

Thus, endocrine disruptors like the endogenous hormones may act at any stage of the disease. On the one hand they may act along with the hormones but they may also have hormone-independent epigenetic effects. As the disease takes years or decades to become clinically apparent a myriad of exposures will have occurred making it impossible to discern which of them is relevant to the disease. Once diagnosis is made and levels of chemicals measured, the information obtained may not be necessarily informative.

\section{Lessons from the DES Story: A New Dimension to the Cancer Problem}

In addition to acting at distinct stages of tumorigenesis as tumor initiators and/ or tumor promoters, endocrine disruptors are adding a new dimension to the cancer problem. This insight was gained from the diethylstilbestrol (DES) experience. DES is an orally active synthetic estrogen that was first synthesized in 1938 and prescribed by doctors in the United States from 1940 to 1971 to help pregnant women who had had miscarriages or premature deliveries in the past. It was given to about 4 million women during this time. The use of DES declined in the 1960s after studies had shown that it might not prevent pregnancy complications. In 1971, the Food and Drug Administration advised doctors to stop prescribing DES during pregnancy when it was estab- lished that the drug could interfere with the development of the reproductive system in a fetus when it was given during the first five months of a pregnancy.

DES was linked to a rare cancer called clear cell carcinoma of the vagina and cervix in daughters of women who used DES during pregnancy.[20] This cancer of the vagina or cervix usually occurs in DESexposed daughters in their late teens or in their early 20s. DES-exposed daughters are about 40 times more likely to develop this cancer than women not exposed to DES in the womb and they also have an increased risk of developing abnormal, premalignant cells in the tissue of the cervix and vagina.

These observations were the first indication that exposure to endocrine-disrupting substances in utero can confer an increased cancer risk in humans. What about breast cancer? Consistent with the previous studies showing that exogenous hormones affect breast cancer risk as discussed above, women who were given DES were found to have an about $30 \%$ higher risk of breast cancer than women who had not been exposed to this drug ${ }^{[21,22]}$ increasing the likelihood of getting the disease from 1 in 8 up to 1 in 6 . The question of whether the DES daughters would show increased breast cancer incidence has long awaited a response as these women needed to reach the age at which breast cancer normally occurs. In 2006, a study, which followed more than 5000 women who had been exposed to DES in utero, found a 1.9 relative risk for breast cancers at over 50 years of age. ${ }^{[23]}$ This is the first evidence in humans that exposure cancer after age 40 and 3.0 relative risk for 
to endocrine disruptors in utero can affect breast cancer risk.

A similar link between the uterine environment and breast cancer risk had been suggested by the observation that factors such as twin pregnancies and maternal preeclampsia, two conditions with increased estrogen levels, confer increased breast cancer risk on the offspring. ${ }^{[24,25]}$ This raises the concern that environmental exposures, although they are very subtle, may need to be considered more seriously because they are so prevalent. Evidence has accumulated from animal models that low dose exposure both in utero and in the adult organism has effects on various organ systems, among them the breast.

\section{The Case of Bisphenol A}

A compound that is structurally closely related to DES is bisphenol A (BPA, 2,2-bis-(4hydroxyphenyl) propane). It was developed before DES but initially rejected for medical applications as it was too weakly estrogenic. Later BPA found its way on a different market and is produced in large amounts, 2.2 million tonnes world-wide in 2003.[26] BPA is primarily used in the synthesis of polycarbonate plastic, epoxy resins and as an additive to other plastics. Because of its presence in many consumer goods such as food containers, dental sealants, some flame retardant and water supply pipes, there is widespread human exposure. ${ }^{[27,28]}$ Plasma levels of BPA in pregnant women show a range between 0.3 and 18.9 $\mathrm{ng} / \mathrm{ml}$.[29]

Environmentally relevant doses have been administered to different animal models and a plethora of effects has been revealed. Exposures of animals both as adults and in utero result in changes in various organ systems such as the brain, the reproductive system, and the immune system. ${ }^{[30]}$

Estrogens bind to two different nuclear hormone receptors, the estrogen receptor $\alpha(\mathrm{ER} \alpha)$ and its cousin, the estrogen receptor $\beta(\mathrm{ER} \beta)$. In addition to interacting with the ER $\alpha$, which is the important form in the breast ${ }^{[31]}$ and in other female reproductive organs, ${ }^{[32]}$ BPA actually binds with higher affinity to its cousin the ER $\beta$, which is expressed in almost all tissues of the body. Furthermore BPA binds, albeit with lower affinity to the androgen receptor ${ }^{[33,34]}$ and the thyroid receptor. ${ }^{[35]}$ BPA has been shown to modify both expression and activity of cytochrome $\mathrm{p} 450^{[36,37]}$ and can act epigenetically by down-modulating gene expression through methylation, ${ }^{[38]}$ (for a detailed review of the mechanisms of action of BPA the reader is referred to ref. [39]).

BPA perinatal exposure triggers premature onset of puberty.[40] This in itself could indirectly contribute to an increase

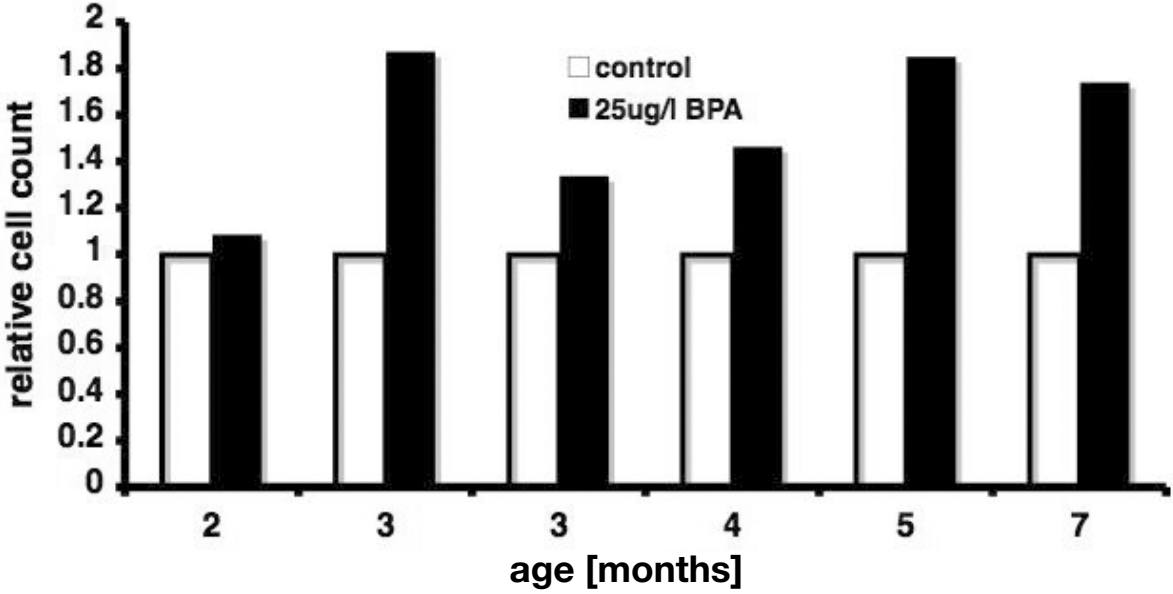

Fig. 2. Perinatal BPA exposure increases cell numbers in the mammary gland: Graph representing cell counts taken in six independent experiments. Age of mice (either 2 or 3 per group) in months is plotted on the $x$ axis, the relative cell counts are plotted on the $y$-axis. Open bars represent mice that were not exposed to BPA closed bars represent mice whose parents drank water with $25 \mu \mathrm{g}$ of BPA/liter, the calculated exposure is $2.5 \mu \mathrm{g} / \mathrm{kg}$ bodyweight per day. Note that mammary glands from exposed mice show consistently higher cell counts that the mammary glands from unexposed controls.

in breast cancer risk as early menarche is a risk factor. However, the work of Dr. Soto and colleagues established that perinatal BPA exposure at environmentally relevant concentrations alters breast development in both outbred mice ${ }^{[41,42]}$ and in rats ${ }^{[43]}$ with changes that cannot be explained by the earlier onset of puberty, pointing to additional biological activities of BPA with regards to the mammary gland. In rats, which were exposed to BPA in utero hyperplasias and dysplasias, tumor precursor lesions, were detected in the mammary glands of adult rats. ${ }^{[43]}$

\section{Mechanisms of BPA in vivo}

In the framework of the NRP50 programme we set out to look at the mechanisms underlying the changes elicited by BPA in vivo. Because of the myriad of interactions in endocrine signaling at the organismal level it is difficult to dissect mechanisms in in vivo models. As a first step we reduced biological variation by using inbred rather than outbred mice used in previous experiments. We chose the C57B16 mouse strain chosen because it is frequently used for genetic manipulations of the mouse germline allowing us to make use of mouse strains with specific gene deletions. However, C57B16 mice were known to breed less well and have dampened responses to estrogens compared to outbred mice, raising the concern that the subtle biological effects of BPA administration would be difficult to discern. Concomitantly, we changed the route of administration from the subcutane- ously implanted drug releasing pumps used previously to oral administration to breeding mice via drinking water in order to more closely mimic the human situation where exposure is oral. In this way the offspring was exposed during intrauterine development and during the first three weeks of life through the mothers' milk. Upon weaning the pups were housed in cages with BPAfree drinking water.

As observed previously, the development of the milk ducts in pubertal mice showed a biphasic response to low dose BPA with maximal effect at $2.5 \mu \mathrm{g} / \mathrm{kg}$ bodyweight/day; the range tested extended from $25 \mathrm{ng} / \mathrm{kg}$ bodyweight/day to $250 \mu \mathrm{g} /$ $\mathrm{kg}$ bodyweight /day (Mallepell et al., unpublished observations). Changes in the layout of the ductal tree in adult females were not detected. However, counts of the cells making up the milk ducts, a more sensitive approach to reveal increased proliferation than the morphological evaluation, revealed that the epithelial cell numbers were consistently increased about 1.5 fold (Mallepell et al., unpublished observations, Fig. 2) in adult mice. This observation is of concern as an increase in epithelial cell number reflects an increase in the number of cells that can potentially undergo malignant changes. At the population level even a minor increase in risk can have large consequences when a disease is very prevalent such as breast cancer.

To address whether BPA exposure changes the endocrine milieu or the breast epithelium itself, we grafted epithelial cells from exposed mice into untreated mice. The grafted epithelium retained features 
that had been induced by the exposure in utero when it was growing in an unexposed host. This indicates that permanent changes in the epithelium have occurred that persist in a normal endocrine milieu (Mallepell et al., unpublished observations), whether these changes were elicited by direct action of BPA on the mammary epithelium or are indirect effects of BPA acting on the mammary stroma or in other organs remains to be addressed. In any case, the identification of these persistent changes in a specific cell type opens the possibility to perform further analyses to identify specific biochemical changes.

Investigations are ongoing with mice lacking either one or both copies of the $\mathrm{ER} \alpha$ and/or the ER $\beta$ gene to assess to what extent the two proteins are involved in mediating the changes elicited by BPA.

\section{Perspectives}

Although research indicates that manmade chemicals may be causing problems in wildlife, at least in localized areas, it is still difficult to determine which hormone mimics pose what health risks for people. The studies on DES patients and their offspring indicate that humans are also susceptible to endocrine disruptors at different developmental stages. Evidence from animal model with environmentally relevant doses of BPA establishes a role of endocrine disruption in breast and in prostate cancer (not discussed here). The studies illustrate the complexity of the mechanisms of action and its biological effects. BPA however is only one of a myriad of factors that we are exposed to. So should we ignore warning signs or is it time to take the issue into consideration in order to elaborate a preventive public health policy?

Received: March 22, 2008

[1] I. O. Ellis, S. J. Schnitt, X. Sastre-Garau, G. Bussolati, F. A. Tavassoli, V. Eusebi, J. L. Peterse, K. Mukai, L. Tabár, J. Jacquemier, C. J. Cornelisse, A. J. Sasco, R. Kaaks, P. Pisani, D. E. Goldgar, D. Devilee, M. J. Cleton-Jansen, A. L. Børrensen-Dale, L. van't Veer, A. Sapino, 'Invasive Breast Carcinoma', in 'Pathology and Genetics of Tumours of the Breast and Female Genital Organs', Ed. F. Tavassoli, P. Devilee, vol. 5, IARC Press, Lyon, 2003, p. 13.

[2] D. M. Parkin, F. I. Bray, S. S. Devesa, Eur. J. Cancer 2001, 37, S4.
[3] L. Garfinkel, C. C. Boring, C. W. Heath, Jr., Heath. Cancer 1994, 74, 222.

[4] C. Bouchardy, G. Fioretta, H. M. Verkooijen, G. Vlastos, P. Schaefer, J. F. Delaloye, I. Neyroud-Caspar, S. Balmer Majno, Y. Wespi, M. Forni, P. Chappuis, A. P. Sappino, E. Rapiti, Br. J. Cancer 2007, 96, 1743

[5] N. Hamajima, K. Hirose, K. Tajima T. Rohan, E. E. Calle, J. R. Heath, R. J. Coates, J. M. Liff, R. Talamini, N. Chantarakul, P. Chappuis, A. P. Sappino, E. Rapiti, Br. J. Cancer 2002, 87, 1234.

[6] P. A. van den Brandt, D. Spiegelman, S. S. Yaun, H. O. Adami, L. Beeson, A. R. Folsom, G. Fraser, R. A. Goldbohm, S. Graham, L. Kushi, J. R. Marshall, A. B. Miller, T. Rohan, S. A. Smith-Warner, F. E. Speizer, W. C. Willett, A. Wolk, D. J. Hunter, Am. J. Epidemiol. 2000, 152, 514.

[7] J. L. Kelsey, M. D. Gammon, E. M. John, Epidemiol. Rev. 1993, 15, 36.

[8] J. R. Harris, M. E. Lippman, U. Veronesi, W. Willett, N. Engl. J. Med. 1992, 327, 319.

[9] Collaborative Group on Hormonal Factors in Breast Cancer, Lancet 1996, 347, 1713.

[10] V. Beral, Lancet 2003, 362, 419.

[11] U. G. Ahlborg, L. Lipworth, L. TitusErnstoff, C. C. Hsieh, A. Hanberg, J. Baron, D. Trichopoulos, H. O. Adami, Crit. Rev. Toxicol. 1995, 25, 463.

[12] A. M. Soto, K. L. Chung, C. Sonnenschein, Environ. Health Perspect. 1994, 102, 380.

[13] D. J. Bustos, F. Diaz, A. N. Tchernitchin, Bull. Environ. Contam. Toxicol. 1988, 1 , 91.

[14] M. Crausaz, J. Vargas, R. Parapanov, Y. Chollet, M. Wisard, E. Steller, A. Senn, M. Germond, Chimia 2008, 62, 395.

[15] A. P. Hoyer, P. Grandjean, T. Jorgensen, J. W. Brock, H. B. Hartvig, Lancet 1998 352,1816

[16] S. F. Arnold, P. M. Vonier, B. M. Collins, D. M. Klotz, J. R. Guillette, J. A. McLachlan, Environ. Health Perspect. 1997, 105, 615.

[17] M. D. Anway, A. S. Cupp, M. Uzumcu, M. K. Skinner, Science 2005, 308, 1466.

[18] M. D. Anway, C. Leathers, M. K. Skinner, Endocrinology 2006, 147, 5515.

[19] C. Brisken, S. Duss, Stem Cell. Rev. 2007, 3,147 .

[20] A. L. Herbst, H. Ulfelder, D. C. Poskanzer, N. Engl. J. Med. 1971, 284, 878.

[21] E. R. Greenberg, A. B. Barnes, L. Resseguie, J. A. Barrett, S. Burnside, L. L. Lanza, R. K. Neff, M. Stevens, R. H. Young, T. Colton, N. Engl. J. Med. 1984, 311,1393

[22] T. Colton, E. R. Greenberg, K. Noller, L. Resseguie, C. Van Bennekom, T. Heeren, Y Zhan, Jama 1993, 269, 2096.

[23] J. R. Palmer, L. A. Wise, E. E. Hatch, R. Troisi, L. Titus-Ernstoff, W. Strohsnitter, R. Kaufman, M. L. Herbst, K. L. Noller,
M. Hyer et al. Cancer Epidemiol. Biomarkers Prev. 2006, 15, 1509.

[24] H. A. Weiss, N. A. Potischman, L. A Brinton, D. Brogan, R. J. Coates, M. D. Gammon, K. E. Malone, J. B. Schoenberg, Epidemiology 1997, 8, 181

[25] A. Ekbom, C. C. Hsieh, L. Lipworth, H. Q. Adami, D. Trichopoulos, J. Natl. Cancer Inst. 1997, 89, 71.

[26] E. Burridge, Eur. Chem. News 2003, 17, 14.

[27] A. M. Calafat, Z. Kuklenyik, J. A. Reidy, S. P. Caudill, J. Ekong, L. L. Needham, Environ. Health Perspect. 2005, 113, 391.

[28] J. H. Kang, F. Kondo, Y. Katayama, Toxicology 2006, 226, 79 .

[29] G. Schonfelder, W. Wittfoht, H. Hopp, C. E. Talsness, M. Paul, I. Chahoud, Environ. Health Perspect. 2002, 110, A703.

[30] C. A. Richter, L. S. Birnbaum, F. Farabollini, R. R. Newbold, B. S. Rubin, C. E. Talsness, J. G. Vandenbergh, D. R Walser-Kuntz, F. S. vom Saal, Reprod. Toxicol. 2007, 24, 199.

[31] S. Mallepell, A. Krust, P. Chambon, C. Brisken, Proc. Natl. Acad. Sci. USA 2006, 103, 2196.

[32] S. Dupont, A. Krust, A. Gansmuller, A. Dierich, P. Chambon, M. Mark, Development 2000, 127, 4277.

[33] P. Sohoni, J. P. Sumpter, J. Endocrinol. $1998,158,327$.

[34] H. J. Lee, S. Chattopadhyay, E. Y. Gong, R. S. Ahn, K. Lee, Toxicol. Sci. 2003, 75 , 40.

[35] R. T. Zoeller, R. Bansal, C. Parris, Endocrinology 2005, 146, 607.

[36] J. M. Cannon, E. Kostoryz, K. A. Russo, R. E. Smith, R. Yourtee, Biomacromolecules 2000, 1,656 .

[37] N. Hanioka, H. Jinno, T. Nishimura, M. Ando, Arch. Toxicol. 1998, 72, 387.

[38] S. M. Ho, W. Y. Tang, G. S. Prins, Cancer Res. 2006, 66, 5624

[39] Y. B. Wetherill, B. T. Akingbemi, J. Kanno, J. A. McLachlan, A. Nadal, C. Sonnenschein, C. S. Watson, R. T. Zoeller, S. M. Belcher, Reprod. Toxicol. 2007, 24, 178.

[40] K. L. Howdeshell, A. K. Hotchkiss, K. A. Thayer, J. G. Vandenbergh, F. S. vom Saal, Nature 1999, 401, 763.

[41] C. M. Markey, E. H. Luque, M. Munoz De Toro, C. Sonnenschein, A. M. Soto, Biol. Reprod. 2001, 65, 1215.

[42] M. Munoz-de-Toro, C.M. Markey, P. R. Wadia, E. H. Luque, B. S. Rubin, C. Sonnenschein, A. M. Soto, Endocrinology 2005, 146, 4138.

[43] M. Durando, L. Kass, J. Piva, C. Sonnenschein, A. M. Soto, E. H. Luque, M. Munoz-de-Toro, Environ. Health Perspect. 2007, 115, 80. 